\title{
REVIEW
}

\section{Traumatic brain injury: Can the consequences be stopped?}

\author{
Eugene Park PhD, Joshua D. Bell BSc, Andrew J. Baker MD
}

\section{ABSTRACT}

Traumatic brain injury is a leading cause of morbidity and death in both industrialized and developing countries. To date, there is no targeted pharmacological treatment that effectively limits the progression of secondary injury. The delayed progression of deterioration of grey and white matter gives hope that a meaningful intervention can be applied in a realistic timeframe following initial trauma. In this review we discuss new insights into the subcellular mechanisms of secondary injury that have highlighted numerous potential targets for intervention.

Une version française de ce résumé est disponible à l'adresse www.cmaj.ca/cgi/content/full/178/9/ri63/DCI

CMAJ 2008;178(9):1163-70

$\mathrm{W}$

e provide an overview of traumatic brain injury and, in particular, the mechanisms of secondary injury and emerging novel concepts for future intervention strategies. Understanding these processes in greater detail can identify feasible time frame for treatment and targets for meaningful interventions.

Severe traumatic brain injury continues to be a leading cause of death and morbidity in North America. ${ }^{1-8}$ The incidence of mild traumatic brain injury is high, and it is a major management problem for clinicians and a considerable source of frustration for patients. The economic and social burden of traumatic brain injury has implications on a global scale, with incidences in developing countries rising as the rate of vehicle use outpaces the development of safety infrastructure. ${ }^{9,10}$ In addition, traumatic brain injury is now a major focus of casualty care in combat areas, as it is the principal cause of mortality and morbidity especially because of the recent surge in the use of low-cost, yet powerful, explosive devices directed at civilian and military personnel. ${ }^{11}$

Extensive literature aimed at understanding the tissue, cellular, inflammatory and subcellular processes following traumatic brain injury have proven unequivocally that these pathophysiological events are delayed and progressive in nature. Although the greatest impact on survival and outcome to date may be attributed to systemic and intracranial physiologic management (e.g., fluid resuscitation, intracranial pressure monitoring), future mitigation of the progression of sec- ondary injury will likely be through molecular, gene and pharmacologic interventions. The prospect of gene therapy and pharmacologic treatments require physicians to be familiar with the subcellular mechanisms of brain injury.

\section{Overview of brain injury}

A patient is described as having a severe traumatic brain injury if he or she remains in a coma (Glasgow Coma Score of 8 or less) following initial resuscitation. These patients often require mechanical ventilation and invasive monitoring of intracranial pressure. The mortality is between $30 \%-50 \%$ and is higher among older patients. ${ }^{12}$ Among patients who die from traumatic brain injury, about $90 \%$ die within 48 hours of injury, usually because of uncontrolled raised intracranial pressure leading to brain stem herniation and death by neurologic criteria. ${ }^{13}$ Delayed deaths are caused by either complications in critically ill patients or by decisions to withdraw invasive physiologic support from patients unable to survive without this life support.

Mild traumatic brain injury is much more difficult to define and is likely considerably underdiagnosed. Incidence estimates vary widely, but it may affect Ioo-600 per 100 o०o people annually. ${ }^{14,15}$ Early identification usually includes a history of direct trauma to the head and brief loss of consciousness. However, mild traumatic brain injury also occurs following acceleration-deceleration forces without direct trauma and often without explicit loss of consciousness. Ongoing symptoms include headache, dizziness and concentration, memory and other neuropsychiatric and cognitive complaints and findings. This is a problem for which there is increasing awareness and identification as well as increasing knowledge of the biological basis of the symptoms.

Approaches to preventing traumatic brain injury can be described as primary, secondary and tertiary. Primary prevention aims to prevent the trauma altogether. Efforts range from changing public policies (e.g., speed limits, helmet use, safety standards, road engineering) to changing public culture (e.g., alcohol abuse, helmet use in recreational activities and preventing sports-related concussions). Secondary pre-

From the Cara Phelan Centre for Trauma Research (Park, Bell, Baker), Keenan Research Centre, Li Ka Shing Knowledge Institute, St. Michael's Hospital; and the Institute of Medical Science, Departments of Anesthesia and Surgery (Bell, Baker), University of Toronto, Toronto, Ont. 


\section{Key points}

- Severe traumatic brain injury is a leading cause of morbidity and mortality worldwide.

- Abnormal intracellular calcium homeostasis is a central feature of both grey and white matter secondary injury.

- White matter injury is important in the prognosis of both severe and mild injury.

- Recent studies point to trauma-induced changes in neuronal receptor composition that render cells vulnerable to delayed injury.

vention is aimed at minimizing the whole biological injury resulting from the trauma. Tertiary prevention refers to maximizing patients' functional abilities and restoring their daily life following an established brain injury. These include various approaches to neuro-rehabilitation as well as symptom management. Tertiary prevention also includes increasing awareness of the consequences of mild traumatic brain injury and understanding the relation between imaging, function and underlying pathology.

\section{Secondary prevention and injury}

Secondary prevention comprises minimizing the biological injury arising from the immediate physical trauma and maximizing the biological potential for tertiary prevention. Although concepts of tertiary prevention are now being incorporated into the early management of traumatic brain injury, secondary prevention is the primary focus of prehospital and acute health care delivery. Central to these efforts are 2 assumptions: there are evolving and delayed biological injuries following trauma ("secondary injury"); and interventions directed at secondary injury can make a difference. Certainly the most dramatic evidence for the first concept is a patient who, following traumatic brain injury, "talks and dies" - that is a patient who, at first, is able to verbalize sensibly but subsequently deteriorates, typically because of delayed or evolving intracranial hemorrhage, and dies from rapidly progressive raised intracranial pressure. The early removal of various types of traumatic intracranial hematoma can change the outcome for these patients. Over the last few decades, we have learned much about factors associated with worse outcomes following traumatic brain injury, such as hypotension and hypoxia. It is likely that advances in prehospital care or transport as well as advances in critical care, which have resulted in the reduction of hypoxia and hypotension, may be the reason for the improved outcomes we have witnessed following severe traumatic brain injury.

There is a substantial body of work that has analyzed other systemic and intracranial physiologically targeted interventions that might reduce secondary injury and make a difference in outcomes. These include the analysis of prehospital factors, choice of fluid for resuscitation, blood-pressure management, temperature management, intracranial pressure management, oxygenation parameters and ventilation techniques. These have resulted in the publication of practice guidelines for severe traumatic brain injury. ${ }^{16}$ Similarly, there is literature that involves the early clinical identification and diagnosis of mild traumatic brain injury and its early and ongoing management. However, much of this work is aimed at the early initiation of strategies for tertiary prevention.

In addition to clinical systemic approaches and those directed by intracranial physiology, clinical studies of interventions targeted at reducing secondary injury arising from discrete subcellular processes (e.g., toxicity due to reactive oxygen species, overstimulation of glutamate receptors, excessive influx of calcium and inflammatory upregulation) have not resulted in a standard drug treatment. This likely reflects both the complexity of the mechanisms of secondary injury as well as issues of drug dosing and timing and the lack of specificity of drug effects. ${ }^{17,18}$ In the last Io years, further exploration into the mechanisms underlying the failure of subcellular treatments for secondary injury has revealed a greater than anticipated complexity of molecular processes, but it has also revealed novel targets with higher probabilities of success. Bridging these knowledge gaps is paramount to developing effective future treatments.

\section{Basic biological mechanisms}

Although primary injury comprises the initial tear, shear or hemorrhage, the mechanisms of secondary injury can dramatically exacerbate the initial injury. However, the delayed process of secondary injury allows hope for meaningful intervention. Secondary injuries are multiple, parallel, interacting and interdependent cascades of biological reactions caused by primary injury. The major known pathways are summarized in Figure I and some clinical manifestations are illustrated in Figure 2.

In general, the ongoing sequelae of damage to nervous tissue is perpetuated by the early failure of neuronal energy, glial injury and dysfunction (swelling of astrocytic foot processes, reversal of neurotransmitter reuptake and reactive astrocytosis), inflammation (invasion of the injury site by microglia and release of proinflammatory cytokines), destruction and stenosis of microvasculature, excitotoxicity and aberrant ionic homeostasis in neurons, and progressive white matter deterioration (Box I).

\section{White matter injury}

White matter - the part of the brain that provides long connections between different parts of the grey matter or cortex - exhibits different patterns of deterioration compared with grey matter. Traumatic axonal injury is a common occurrence in both focal and diffuse brain trauma regardless of injury severity. ${ }^{19-22}$ Traumatic axonal injury has proven to be a reliable predictor of poor survival or poor long-term outcome $e^{23-26}$ yet it is frequently underdiagnosed, particularly in mild traumatic brain injury owing to a lack of tools with sufficient thresholds of detection. Importantly, we now understand that there are mechanisms leading to delayed white matter injury beyond the direct initial consequence of shear forces generated at the moment of initial trauma. Following trauma to the head, especially with rotational forces, it is possible to identify axonal shearing from primary injury. However, a greater number of axons undergo disconnection, or secondary axo- 
tomy, at later times. ${ }^{27}$ Immunohistochemical markers of axonal injury, advanced imaging technologies and serum biomarkers have demonstrated that white matter injury is in fact a progressive and delayed degenerative process. This occurs in both severe and mild traumatic brain injuries.

Abnormal calcium homeostasis is a critical component of the progression of secondary injury in both grey and white matter. In neuronal cell injury, it is associated with excitotoxic cell death, initiation of programmed cell death and postsynaptic receptor modifications. In axonal injury, calcium initiates a cascade of events culminating in axonal disconnection. In both neuronal and axonal injury, calcium overload is linked to early mitochondrial swelling. ${ }^{28,29}$ Excessive sequestration of calcium by mitochondria causes its membrane depolarization, the opening of membrane permeability transition pores and the release of initiating factors of programmed cell death. ${ }^{30,31}$ The loss of mitochondrial function not only eliminates calcium buffering capacity but also contributes to the influx of calcium resulting from bioenergetic failure of ATP-dependent ion pumps. For example, cyclosporin A, an immunosuppressant and inhibitor of the mitochondrial membrane-permeability-transition pore, has been shown to reduce both axonal pathology and neuronal cell loss, thus illustrating the importance of this process. ${ }^{32-35}$

White matter injury is increasingly recognized as central to the impact on the quality of life of patients with either severe or mild traumatic brain injury. After severe injury, damage to the major white matter tracts is devastating and, despite normal intracranial pressure, it can be the determinant of death or persistent disability (Figure 3). Following mild traumatic brain injury, white matter lesions may be the determinant of ongoing symptoms as well as patients' increased susceptibility to future traumatic events.

The important secondary injury of white matter involves the axonal membrane becoming "leaky" (a state permitting an influx of extracellular calcium). ${ }^{36-38}$ As a result of increased

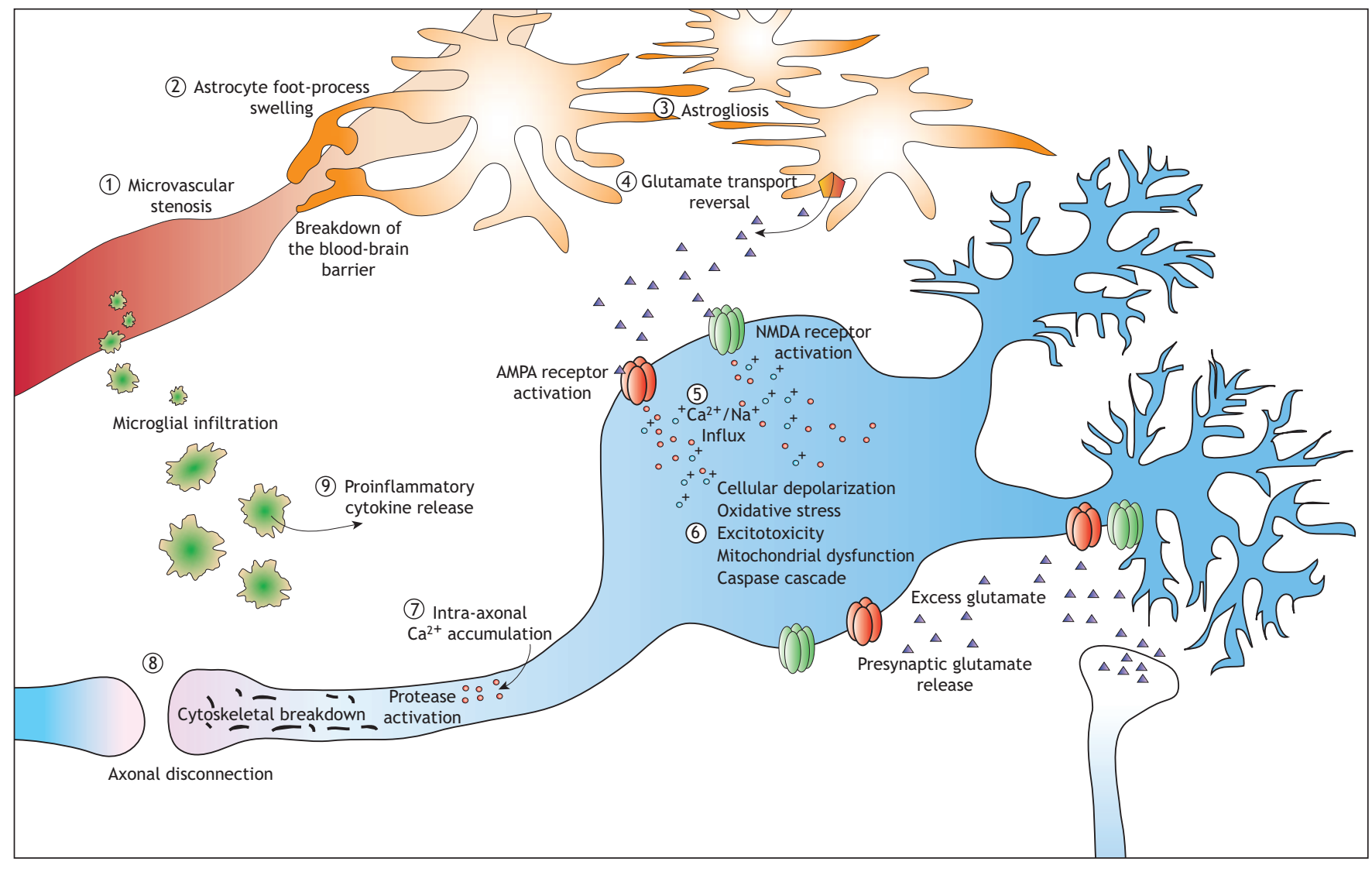

Figure 1: The major pathways associated with the progression of secondary injury after a traumatic brain injury. Microcirculatory derangements involve stenosis (1) and loss of microvasculature, and the blood-brain barrier may break down as a result of astrocyte foot processes swelling (2). Proliferation of astrocytes ("astrogliosis") (3) is a characteristic of injuries to the central nervous system, and their dysfunction results in a reversal of glutamate uptake (4) and neuronal depolarization through excitotoxic mechanisms. In injuries to white and grey matter, calcium influx (5) is a key initiating event in a molecular cascades resulting in delayed cell death or dysfunction as well as delayed axonal disconnection. In neurons, calcium and zinc influx though channels in the AMPA and NMDA receptors results in excitotoxicity (6), generation of free radicals, mitochondrial dysfunction and postsynaptic receptor modifications. These mechanisms are not ubiquitous in the traumatized brain but are dependent on the subcellular routes of calcium influx and the degree of injury. Calcium influx into axons (7) initiates a series of protein degradation cascades that result in axonal disconnection (8). Inflammatory cells also mediate secondary injury, through the release of proinflammatory cytokines ( 9 ) that contribute to the activation of cell-death cascades or postsynaptic receptor modifications. 
calcium concentrations in the axon, enzymes that degrade key structural proteins become activated and destroy proteins responsible for the maintenance of shape and transport in axons. These events cause the accumulation of transported proteins, axonal swelling and, ultimately, disconnection ${ }^{39}$

Activation of protein-targeting enzymes after trauma can result in the production of distinct protein fragments. The identification of these signature markers through proteomic

\section{Box 1: Glossary of terms}

oll-spectrin: A structural protein involved in the maintenance of axonal shape. A key target of calpains after trauma.

AMPA ( $\alpha$-amino-3-hydroxy-5-methyl-4-isoxazolepropionic acid): Chemical agonist selective for the AMPA class of excitatory glutamate receptors.

Ionic homeostasis: The naturally occurring gradient of intracellular ion concentrations within a cell.

$\beta$-amyloid precursor protein: A protein transported by axons. It can be used as an immunohistochemical marker of axonal injury. This protein accumulates in injured axons with impaired transport and contributes to axonal swelling.

Calpains: A family of enzymes that degrade numerous intracellular proteins. Calpains are activated by high levels of intracellular calcium.

Caspase-3: A calcium-activated enzyme referred to as the "executioner caspase" because of its role in initiating programmed cell death.

Cytoskeleton: Proteins that comprise the cell's structural "skeleton."

Excitoxicity: Over-activation of glutamate receptors leads to a massive sodium and calcium influx that results in rapid cell death.

GluR2: The AMPA-receptor subunit that determines whether the receptor is permeable to calcium. AMPA receptors that include the GluR2 subunit are not permeable to calcium.

Immunohistochemistry: A technique used to visually identify specific proteins in tissues by use of antibodies against specific antigens.

NMDA ( $\mathrm{N}$-methyl-D-aspartic acid): Chemical agonist selective for the NMDA class of glutamate receptors

Primary cell culture: A laboratory technique of growing cells on a plate. Primary cell culture is often used for in vitro experiments.

Reactive astrocytosis: A characteristic response of astrocytes (subtype of glial cells) to injuries of the central nervous system. It includes proliferation and processes extension, and it can be visualized by histological examination of increased expression of an astrocyte marker (glial fibrillary aidic protein).

Secondary axotomy: The process by which axons become disconnected after a delay following initial trauma. Occurs as the result of subcellular events not the force of the initial injury.

Superoxide, peroxynitrite, nitric oxide: Reactive oxygen species that can contribute to the destruction of cell membranes and DNA breakdown leading to cell death.

Traumatic axonal injury: The delayed and progressive deterioration of white matter following trauma.

Tumour necrosis factor $\alpha$ : A cytokine secreted by inflammatory cells that is capable of initiating cell-death pathways as well as modulating glutamate-receptor composition. screening technologies has high diagnostic potential for determining the nature and severity of injury as well as potential therapeutic targets. ${ }^{40}$

One family of ubiquitous enzymes, calpains, has received considerable attention as key mediators of axonal injury. Given the profound protection conferred by pharmacologic antagonists in animal models, these enzymes may also be potential therapeutic targets for white matter injury. ${ }^{41-43}$ Under normal physiologic conditions (low intracellular calcium), calpains have a wide range of targets with numerous regulatory functions. ${ }^{44,45}$ Under pathophysiological conditions, however, calpains target axonal proteins responsible for structure and transport. ${ }^{45-47}$ A particular axonal protein expressed exclusively in the brain, $\alpha$ II-spectrin, provides an example of how the diagnosis of white matter injury may be aided by proteomic technologies. Calpain-mediated breakdown of $\alpha$ II-spectrin results in the production of 2 specific fragments (I50 kDa and I45 kDa). ${ }^{48,49}$ In contrast, caspase- 3 cleavage (typically associated with programmed cell death) of $\alpha$ IIspectrin results in a $150 \mathrm{kDa}$ and a $120 \mathrm{kDa}$ fragment. ${ }^{48}$ This distinction allows the dominant process to be determined and holds potential for diagnosis and directed drug design.

Several conventional histologic markers used to characterize traumatic injury to axons include the degradation of several intra-axonal cytoskeletal proteins and the accumulation of transported proteins, such as $\beta$-amyloid precursor protein. ${ }^{50-52}$ As an increasing number of markers of white matter injury are elucidated, it is becoming evident that histologic examination of a few select markers does not reflect the full extent of axonal injury because of the diverse spectrum of mechanisms that can occur as a function of injury severity, location and tissue type. A key stumbling block in the development of treatments for white matter injury is identifying the mechanisms that are most damaging or, more realistically, interventions that can be applied within a reasonable time frame.

Although histologic markers can be used to characterize the pathological events that occur in white matter, the effective translation of basic research findings into meaningful clinical therapy ultimately depends on the functional outcome of white matter. In this regard, electrophysiological assessments in experimental laboratories have shed light on interventions that translate to functionally measurable outcomes. These experimental techniques have been used to track the functional deterioration of white matter after trauma, to identify subpopulations of axons that are more vulnerable than others and to evaluate potential therapeutic treatments for the deterioration of white matter. ${ }^{53-56}$

Studies have revealed that white matter trauma is an active progressive process. Following trauma, white matter exhibits active lesions of inflammation, cytoskeletal breakdown and, finally, axonal disconnection. It is a phenomenon known to occur across a range of injury severities. Further complicating the issue is the finding that all axons are not created equal, with varying susceptibilities dependent on subcellular make-up. We are beginning to recognize that white matter lesions may be responsible for more symptoms than previously thought and that they may be the source of the ongoing neuro-cognitive issues that affect patients following mild traumatic brain injury. 


\section{Excitotoxicity}

Following traumatic brain injury there are excessive extracellular concentrations of the excitatory neurotransmitter glutamate (reviewed by Van Landeghem and colleagues ${ }^{57}$ and Yi and $\mathrm{Hazell}^{58}$ ). Failure of presynaptic membrane-bound ion pumps and calcium-mediated exocytosis is thought to contribute in large part to the initial depolarization-dependent release of glutamate from the neurons. ${ }^{50-61}$ This excess neurotransmission is thought to contribute to the toxic increase in intracellular calcium concentrations. However, more recent theories suggest that excitotoxicity can occur because of

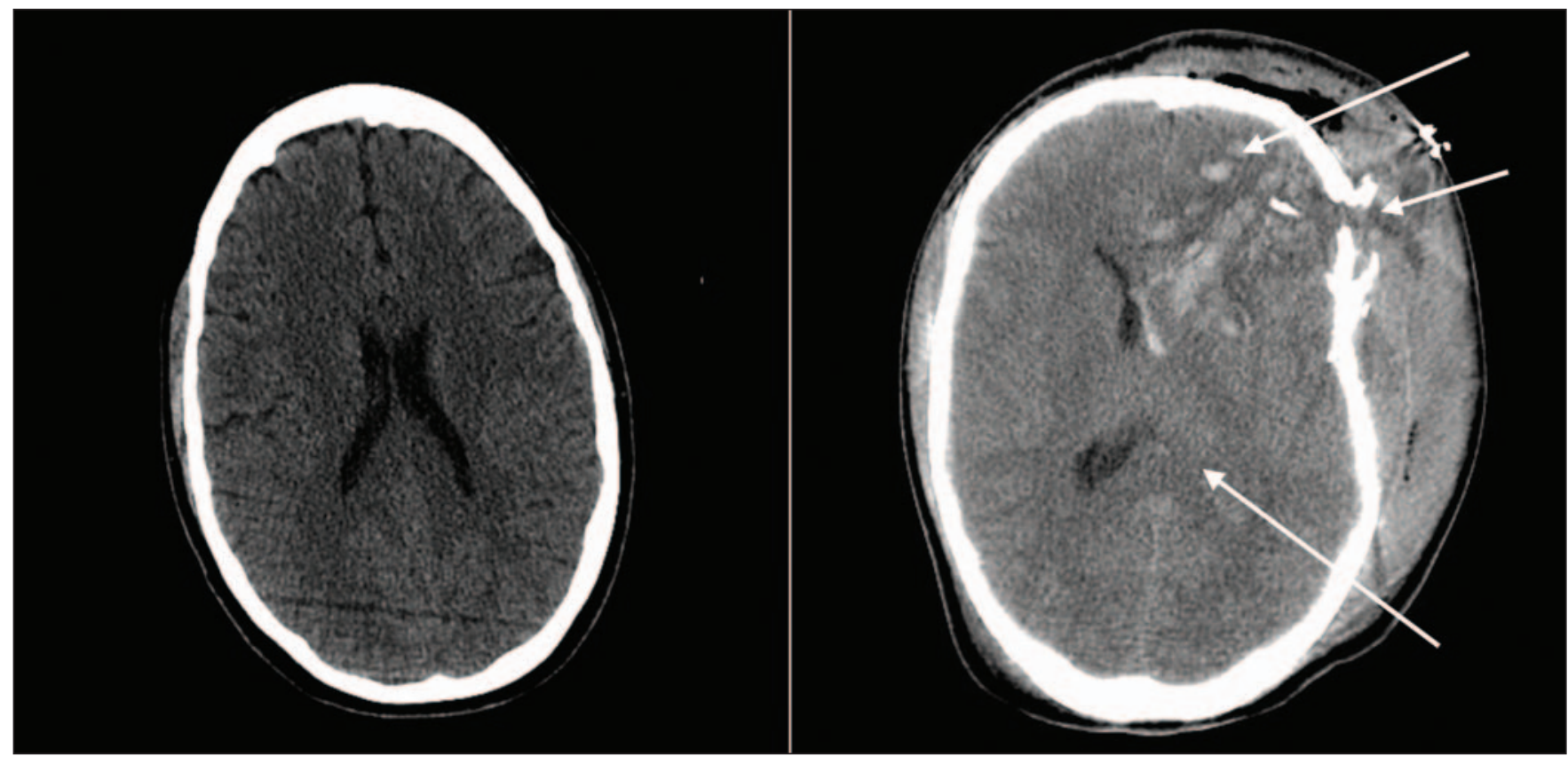

Figure 2: Computed tomography scans of the brain of a 35-year-old man showing normal anatomy and normal-sized ventricles (left) and a 25-year-old man involved in a motor vehicle crash (right), showing frontal contusions, a depressed skull fracture and compressed ventricles (arrow) from cerebral edema and raised intracranial pressure.

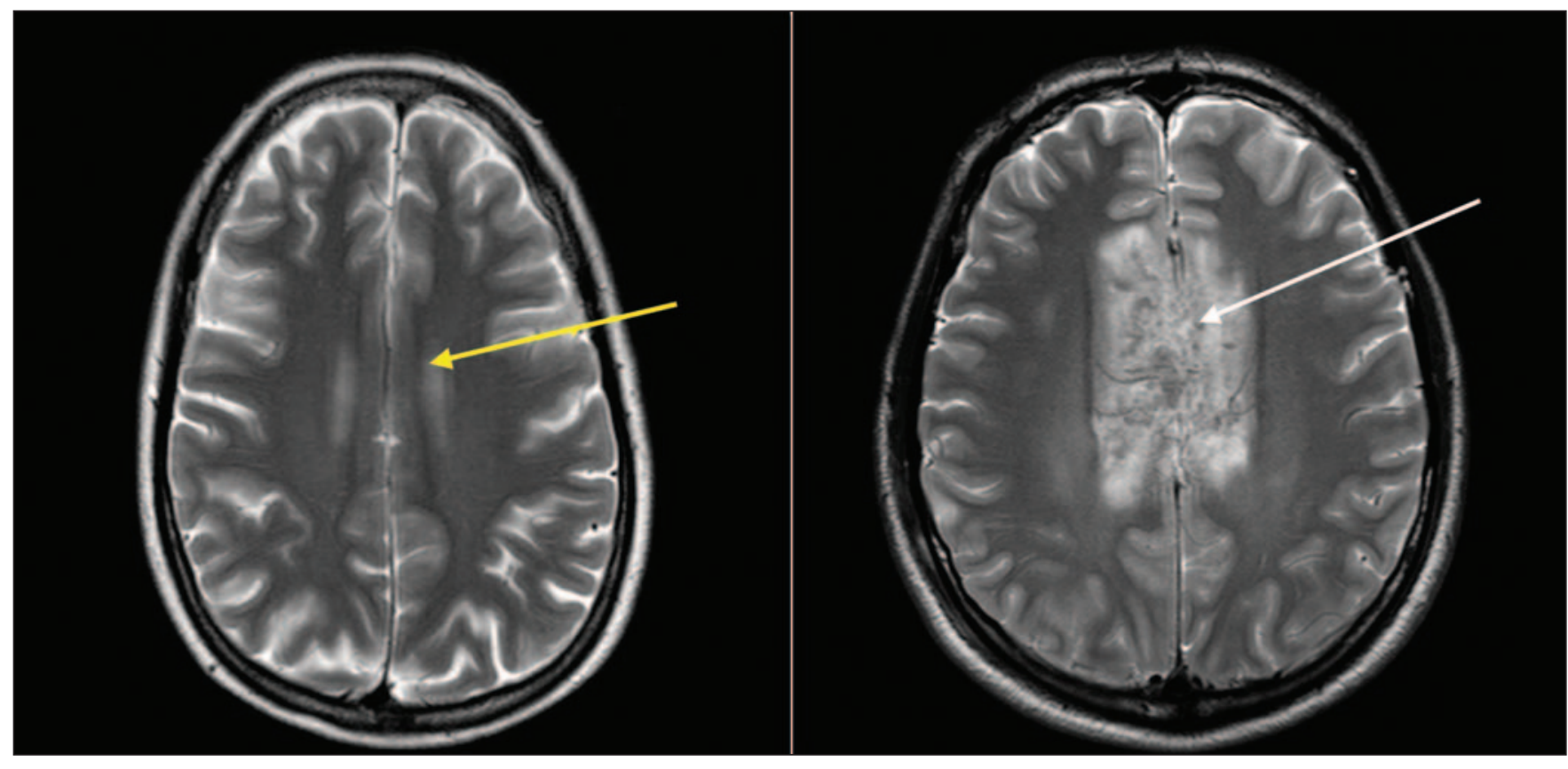

Figure 3: Magnetic resonance images of the brain of a 38 -year-old woman (left) and 35-year-old male passenger in a motor vehicle crash (right) with extensive injury to the corpus callosum (a major tract of white matter between the left and right cerebral cortex) (white arrow). The yellow arrow in the left panel shows an area of the corpus callosum with no edema or disruption. 
trauma-induced changes to postsynaptic glutamate receptor pharmacology, kinetics and subunit composition, and that calcium-mediated toxicity is highly contingent on the location of the calcium influx.

Glutamate receptors can be broadly categorized as AMPA ( $\alpha$-amino-3-hydroxy-5-methyl-4-isoxazolepropionic acid) receptors or NMDA ( $N$-methyl-D-aspartic acid) receptors based on their responsiveness to chemical agonists. Changes to the function of both receptor subtypes have been identified following modelled traumatic brain injury, ultimately leading to calcium overload and neuronal hyperexcitability.

To study trauma-induced changes at the single-cell level, many laboratories make use of primary cell culture models of tissue strain, mimicking on a cell culture plate the type of axonal and somatic stretching that occurs in the brain because of a rapid acceleration-deceleration injury. The most commonly used method involves culturing neurons on a deformable membrane. This model provides a cellular analogue of the changes to angular momentum that occur during rotational head trauma (e.g., whiplash from a car accident, falls from large distances, athletic-related head injury). The length of time over which tissue strain is produced and its intensity can be varied by the researcher. Subsequently, single-cell electrophysiological characterizations of the cell's responses are measured.

\section{AMPA receptors}

A number of groups have identified strain-induced changes to AMPA-receptor transmission. Consistently, traumatic injury to cortical neurons results in an increased current response to AMPA-receptor agonists. Injured neurons display much larger AMPA-receptor ionic currents, potent hyperexcitability, increased free intracellular calcium and susceptibility to otherwise nontoxic concentrations of synthetic glutamate receptor analogues. ${ }^{62-66}$ In the presence of reduced AMPA-receptor desensitization or overactivity, the neurotoxicity of even a brief period of excess synaptic glutamate after trauma can lead to hyperexcitability, epileptic activity or delayed calcium-dependent cell swelling, damage and death. The intracellular mechanisms that regulate the excitability of AMPA receptors are fairly well established and are currently the targets of many investigations seeking to attenuate the altered function of AMPA receptors following acute injury.

AMPA receptors are composed of a combination of 4 subunits (GluRI-4). Receptors lacking the GluR2 subunit are highly permeable to calcium (reviewed by Isaac and colleagues ${ }^{67}$ and Chen and colleagues ${ }^{68}$ ). This has led to the proposal that a reduction in the GluR2 content of synaptic AMPA receptors might underlie the observed abnormal calcium homeostasis or hyperexcitability in the central nervous system after brain trauma. Interestingly, tumour necrosis factor $\alpha$, a proinflammatory cytokine known to infiltrate the injury site following traumatic brain injury, ${ }^{69-72}$ significantly reduces synaptic levels of GluR2 in cultured neurons ${ }^{65,73}$ and increases surface expression of AMPA receptors lacking GluR2. Coupled with increased synaptic glutamate, this remodelling of the composition of AMPA receptors by tumour necrosis factor $\alpha$ (released from injured glia and inflamma- tory cells) leads to post-injury calcium overload. This crosstalk between an inflammatory mediator and glutamatergic neurotransmission sheds new light on how delayed excitotoxicity mediated by AMPA receptors might occur.

It is also known that AMPA receptors lacking GluR2 are highly zinc permeable. ${ }^{67,68}$ Further evidence supporting the hypothesis that there is a reduction of GluR2 following traumatic brain injury is the marked elevation in free ionic zinc in neurons following experimental brain trauma. ${ }^{74-76}$ Free zinc is taken up by mitochondria in an effort to restore zinc homeostasis but, similar to the effects of mitochondrial calcium uptake, this leads to potent mitochondrial dysfunction, prolonged loss of mitochondrial membrane potential and free radical generation. ${ }^{77,78}$ This further implicates the loss of GluR2 as an important step in neuronal death and damage.

\section{NMDA receptors}

In addition to hyperexcitability mediated by AMPA receptors, numerous studies of traumatic neuronal degeneration have implicated excessive activity of NMDA receptors. ${ }^{79-84}$ The intracellular coupling of the NMDA receptor to the generation of reactive oxygen and nitrogen species makes it a deadly route of ion flux (particularly calcium) following a glutamatergic spill. For example, the generation of neuronal nitric oxide is highly dependent on the activity of the NMDA receptor. Though nitric oxide (by definition a free radical) reacts slowly with most biological molecules, when combined with other free radicals (e.g., superoxide generated by compromised mitochondria), it is remarkably reactive. ${ }^{85}$

During periods of excitotoxicity, excessive free calcium is sequestered by the mitochondria in an effort to restore intracellular calcium homeostasis. The elevated calcium level in the mitochondria increases the production of reactive oxygen species, including the superoxide anion. The reaction of mitochondrial-derived superoxide with NMDA-derived nitric oxide produces the highly reactive nitrating species peroxynitrite (an oxidant with activities similar to that of the hydroxyl radical and nitrogen dioxide radical). ${ }^{86}$ Peroxynitrite, produced in excess following experimental traumatic brain injury ${ }^{80,82,87}$ produces nitration of amino acid aromatic rings, ${ }^{85}$ lipid peroxidation ${ }^{88}$ and DNA fragmentation ${ }^{85,89}$ - all of which are rapidly fatal cellular processes.

One of the more promising post-traumatic brain injury therapeutic interventions involves the perturbation of the physical interaction between the NMDA receptor and the generation of neuronal nitric oxide. By severing the interaction between the receptor complex and scaffolding proteins, investigators have successfully attenuated trauma-induced generation of peroxynitrite and nitric oxide in vitro ${ }^{80}$ and have circumvented ischemic infarction in animal models of stroke. ${ }^{90}$ Investigators are currently evaluating the efficacy of this approach in whole animal models of brain injury.

\section{Conclusions}

Our understanding of traumatic brain injury has evolved considerably in the last decade, owing in part to renewed research efforts following a series of ineffective trials targeting 
the mechanisms of secondary injury. There are clearly different mechanisms, both temporal and subcellular, that govern the delayed destruction of white and grey matter. However, in both cases, calcium entry is a critical step in initiating the degenerative processes. A comprehensive understanding of the discrete subcellular mechanisms is critical to bridging the knowledge gaps that will allow effective treatment options to be developed. The problems of mild and severe traumatic brain injury will not be addressed without advances in our ability to prevent secondary injury.

The delayed and active molecular processes involved in white matter deterioration and neuronal cell death gives hope that therapeutic treatment options will be developed. Generalized theories of white matter injury have been challenged by studies illustrating highly complex and parallel mechanisms of injury in axonal subpopulations. Theories of excitotoxicity and cell death have evolved from simple concepts about energy failure and non-specific postsynaptic calcium influx to theories that include distinct trauma-induced alterations to the properties of postsynaptic receptor ion channels and intracellular interactions. An increased awareness of the complexity of secondary injury raises the possibility of more specifically targeted therapeutic strategies, many of which are being currently validated in preclinical studies.

There is no question that primary prevention of severe and mild traumatic brain injury is the desired approach to this common and devastating problem. Nevertheless, advances in the prevention of secondary injury are of great importance for cases in which primary prevention has failed. The goal of clinicians and scientists in this field is to identify the sequence of events in secondary injury with the aim of developing targeted, specific interventions to improve the outcomes of severe and mild traumatic brain injury.

\section{Competing interests: None declared.}

Contributors: Each of the authors contributed to the conception and design of the review, drafted and revised the manuscript for important intellectual content and approved the final version for publication.

\section{REFERENCES}

I. Adekoya N, Thurman DJ, White DD, et al. Surveillance for traumatic brain injury deaths — United States, I989-I998. MMWR Surveill Summ 2002;5I:I-I4.

2. Guerrero JL, Thurman DJ, Sniezek JE. Emergency department visits associated with traumatic brain injury: United States, I995-I996. Brain Inj 2000;I4:I8I-6.

3. Thurman DJ, Alverson C, Dunn KA, et al. Traumatic brain injury in the United States: a public health perspective. J Head Trauma Rehabil I999;I4:602-I5.

4. Sosin DM, Sniezek JE, Thurman DJ. Incidence of mild and moderate brain injury in the United States, I991. Brain Inj 1996;10:47-54.

5. Marshall LF. Epidemiology and cost of central nervous system injury. Clin Neurosurg 2000;46:105-I2.

6. Pickett W, Ardern C, Brison RJ. A population-based study of potential brain injuries requiring emergency care. $C M A J$ 200I;165:288-92.

7. Basso A, Previgliano I, Duarte JM, et al. Advances in management of neurosurgical trauma in different continents. World J Surg 2001;25:1174-8

8. Kelly DF, Becker DP. Advances in management of neurosurgical trauma: USA and Canada. World J Surg 2001;25:1179-85.

9. Mock C, Quansah R, Krishnan R, et al. Strengthening the prevention and care of injuries worldwide. Lancet 2004;363:2172-9.

Io. Finfer SR, Cohen J. Severe traumatic brain injury. Resuscitation 200I;48:77-90.

II. Warden D. Military TBI during the Iraq and Afghanistan wars. J Head Trauma Rehabil 2006;2I:398-402.

I2. Hukkelhoven CW, Steyerberg EW, Rampen AJ, et al. Patient age and outcome following severe traumatic brain injury: an analysis of 5600 patients. J Neurosurg 2003;99:666-73.
I3. Sahuquillo J, Arikan F. Decompressive craniectomy for the treatment of refractory high intracranial pressure in traumatic brain injury. Cochrane Database Syst Rev 2006;(I):CDoo3983.

I4. Cassidy JD, Carroll LJ, Peloso PM, et al. Incidence, risk factors and prevention of mild traumatic brain injury: results of the WHO Collaborating Centre Task Force on Mild Traumatic Brain Injury. J Rehabil Med 2004;(Suppl 43):28-6o.

I5. Holm L, Cassidy JD, Carroll LJ, et al. Summary of the WHO collaborating centre for neurotrauma task force on mild traumatic brain injury. JRehabil Med 2005;37:137-4I.

I6. Guidelines for the management of severe traumatic brain injury. J Neurotrauma 2007;24(Suppl I):SI-Io6

I7. Raghupathi R, McIntosh TK. Pharmacotherapy for traumatic brain injury: a review. Proc West Pharmacol Soc I998;4I:24I-6.

I8. Tolias CM, Bullock MR. Critical appraisal of neuroprotection trials in head injury: What have we learned? NeuroRx 2004;I:7I-9.

I9. Sahuquillo-Barris J, Lamarca-Ciuro J, Vilalta-Castan J, et al. Acute subdural hematoma and diffuse axonal injury after severe head trauma. J Neurosurg I988; 68:894-900.

20. Adams JH, Doyle D, Ford I, et al. Diffuse axonal injury in head injury: definition, diagnosis and grading. Histopathology $1989 ; 15: 49-59$.

2I. Cordobes F, Lobato RD, Rivas JJ, et al. Post-traumatic diffuse axonal brain injury. Analysis of 78 patients studied with computed tomography. Acta Neurochir (Wien) I986;8I:27-35.

22. Gentleman SM, Roberts GW, Gennarelli TA, et al. Axonal injury: A universal consequence of fatal closed head injury? Acta Neuropathol I995;89:537-43.

23. King JT, Carlier PM, Marion DW. Early Glasgow outcome scale scores predict long-term functional outcome in patients with severe traumatic brain injury. J Neurotrauma 2005;22:947-54.

24. Fork $M$, Bartels $C$, Ebert $A D$, et al. Neuropsychological sequelae of diffuse traumatic brain injury. Brain Inj 2005;19:IOI-8.

25. Gusmao SN, Pittella JE. Acute subdural hematoma and diffuse axonal injury in fatal road traffic accident victims: a clinico-pathological study of 15 patients. Arq Neuropsiquiatr 2003;61:746-50.

26. Schaefer PW, Huisman TA, Sorensen AG, et al. Diffusion-weighted MR imaging in closed head injury: high correlation with initial Glasgow coma scale score and score on modified Rankin scale at discharge. Radiology 2004;233:58-66.

27. Maxwell WL, Watt C, Graham DI, et al. Ultrastructural evidence of axonal shearing as a result of lateral acceleration of the head in non-human primates. Acta Neuropathol $1993 ; 86: 136-44$

28. Kim JS, He L, Lemasters J. Mitochondrial permeability transition: a common pathway to necrosis and apoptosis. Biochem Biophys Res Commun 2003;304:463-70.

29. Buki A, Povlishock JT. All roads lead to disconnection? Traumatic axonal injury revisited. Acta Neurochir (Wien) 2006;148:I8I-94.

30. Saelens X, Festjens N, Vande Walle L, et al. Toxic proteins released from mitochondria in cell death. Oncogene 2004;23:286I-74.

31. Stefanis L. Caspase-dependent and -independent neuronal death: two distinct pathways to neuronal injury. Neuroscientist 2005;II:50-62.

32. Buki A, Okonkwo DO, Povlishock JT. Postinjury cyclosporin A administration limits axonal damage and disconnection in traumatic brain injury. J Neurotrauma I999;I6:5II-2I.

33. Okonkwo DO, Buki A, Siman R, et al. Cyclosporin A limits calcium-induced axonal damage following traumatic brain injury. Neuroreport I999;10:353-8.

34. Okonkwo DO, Povlishock JT. An intrathecal bolus of cyclosporin A before injury preserves mitochondrial integrity and attenuates axonal disruption in traumatic brain injury. JCereb Blood Flow Metab 1999;19:443-51.

35. Sullivan PG, Rabchevsky AG, Waldmeier PC, et al. Mitochondrial permeability transition in CNS trauma: Cause or effect of neuronal cell death? J Neurosci Res 2005;79:23I-9.

36. Maxwell WL, McCreath BJ, Graham DI, et al. Cytochemical evidence for redistribution of membrane pump calcium-ATPase and ecto-Ca-ATPase activity, and calcium influx in myelinated nerve fibres of the optic nerve after stretch injury. J Neurocytol I995;24:925-42.

37. Maxwell WL, Kosanlavit R, McCreath BJ, et al. Freeze-fracture and cytochemical evidence for structural and functional alteration in the axolemma and myelin sheath of adult guinea pig optic nerve fibers after stretch injury. $J$ Neurotrauma I999; $6: 273-84$.

38. Wolf JA, Stys PK, Lusardi T, et al. Traumatic axonal injury induces calcium influx modulated by tetrodotoxin-sensitive sodium channels. J Neurosci 200I;21:1923-30.

39. Maxwell WL, Povlishock JT, Graham DL. A mechanistic analysis of nondisruptive axonal injury: a review. J Neurotrauma 1997;I4:419-40.

40. Ottens AK, Kobeissy FH, Fuller BF, et al. Novel neuroproteomic approaches to studying traumatic brain injury. Prog Brain Res 2007;I6I:40I-I8.

4I. Buki A, Farkas O, Doczi T, et al. Preinjury administration of the calpain inhibito MDL-28I70 attenuates traumatically induced axonal injury. J Neurotrauma 2003;20:26I-8.

42. Posmantur R, Kampfl A, Siman R, et al. A calpain inhibitor attenuates cortical cytoskeletal protein loss after experimental traumatic brain injury in the rat. Neuroscience I997;77:875-88.

43. Saatman KE, Murai H, Bartus RT, et al. Calpain inhibitor AK295 attenuates motor and cognitive deficits following experimental brain injury in the rat. Proc Natl Acad Sci USA 1996;93:3428-33.

44. Carafoli E, Molinari M. Calpain: A protease in search of a function? Biochem Biophys Res Commun 1998;247:193-203.

45. Wang KK. Calpain and caspase: Can you tell the difference? Trends Neurosci 2000;23:20-6 
46. Huang Y, Wang KK. The calpain family and human disease. Trends Mol Med 200I;7:355-62.

47. Wang KK, Posmantur R, Nadimpalli R, et al. Caspase-mediated fragmentation of calpain inhibitor protein calpastatin during apoptosis. Arch Biochem Biophys I998;356:187-96.

48. Nath R, Raser KJ, Stafford D, et al. Non-erythroid alpha-spectrin breakdown by calpain and interleukin I beta-converting-enzyme-like protease(s) in apoptotic cells: contributory roles of both protease families in neuronal apoptosis. Biochem J I996;319:683-90.

49. Wang KK, Posmantur R, Nath R, et al. Simultaneous degradation of alphaII- and betaII-spectrin by caspase $3\left(\mathrm{CPP}_{32}\right)$ in apoptotic cells. J Biol Chem 1998;273: 22490-7.

50. McCracken E, Hunter AJ, Patel S, et al. Calpain activation and cytoskeletal protein breakdown in the corpus callosum of head-injured patients. J Neurotrauma I999;16:749-6r.

5I. Sherriff FE, Bridges LR, Gentleman SM, et al. Markers of axonal injury in post mortem human brain. Acta Neuropathol 1994;88:433-9.

52. Smith DH, Uryu K, Saatman KE, et al. Protein accumulation in traumatic brain injury. Neuromolecular Med 2003;4:59-72.

53. Ai J, Liu E, Wang J, et al. Calpain inhibitor MDL-28170 reduces the functional and structural deterioration of corpus callosum following fluid percussion injury. $J$ Neurotrauma 2007;24:960-78.

54. Baker AJ, Phan N, Moulton RJ, et al. Attenuation of the electrophysiological function of the corpus callosum after fluid percussion injury in the rat. J Neurotrauma 2002;19:587-99.

55. Reeves TM, Phillips LL, Lee NN, et al. Preferential neuroprotective effect of tacrolimus (FK506) on unmyelinated axons following traumatic brain injury. Brain Res 2007;1154:225-36

56. Reeves TM, Phillips LL, Povlishock JT. Myelinated and unmyelinated axons of the corpus callosum differ in vulnerability and functional recovery following traumatic brain injury. Exp Neurol 2005;196:126-37.

57. van Landeghem FK, Weiss T, Oehmichen M, et al. Decreased expression of glutamate transporters in astrocytes after human traumatic brain injury. J Neurotrauma 2006;23:1518-28.

58. Yi JH, Hazell AS. Excitotoxic mechanisms and the role of astrocytic glutamate transporters in traumatic brain injury. Neurochem Int 2006;48:394-403.

59. Taylor CP, Meldrum BS. Na+ channels as targets for neuroprotective drugs. Trends Pharmacol Sci I995;16:309-16.

6o. Dirnagl U, Iadecola C, Moskowitz MA. Pathobiology of ischaemic stroke: an integrated view. Trends Neurosci I999;22:39I-7.

6I. Endres M, Dirnagl U. Ischemia and stroke. Adv Exp Med Biol 2002;513:455-73.

62. Goforth PB, Ellis EF, Satin LS. Enhancement of AMPA-mediated current after traumatic injury in cortical neurons. J Neurosci I999;19:7367-74.

63. Bell JD, Ai J, Chen Y, et al. Mild in vitro trauma induces rapid Glur2 endocytosis, robustly augments calcium permeability and enhances susceptibility to secondary excitotoxic insult in cultured Purkinje cells. Brain 2007;130:2528-42.

64. Goforth PB, Ellis EF, Satin LS. Mechanical injury modulates AMPA receptor kinetics via an NMDA receptor-dependent pathway. J Neurotrauma 2004;21:719-32.

65. Stellwagen D, Beattie EC, Seo JY, et al. Differential regulation of AMPA receptor and GABA receptor trafficking by tumor necrosis factor-alpha. J Neurosci 2005;25:3219-28.

66. Liu B, Liao M, Mielke JG, et al. Ischemic insults direct glutamate receptor subunit 2-lacking AMPA receptors to synaptic sites. J Neurosci 2006;26:5309-I9.

67. Isaac JT, Ashby M, McBain CJ. The role of the GluR2 subunit in AMPA receptor function and synaptic plasticity. Neuron 2007;54:859-7I.

68. Kwak S, Weiss JH. Calcium-permeable AMPA channels in neurodegenerative disease and ischemia. Curr Opin Neurobiol 2006;16:28I-7

69. Chen G, Shi JX, Hang CH, et al. Inhibitory effect on cerebral inflammatory agents that accompany traumatic brain injury in a rat model: a potential neuroprotective mechanism of recombinant human erythropoietin (rhEPO). Neurosci Let 2007;425:177-82.

70. Atkins CM, Oliva AA Jr, Alonso OF, et al. Modulation of the cAMP signaling pathway after traumatic brain injury. Exp Neurol 2007;208:145-58.

7I. Crespo AR, Da Rocha AB, Jotz GP, et al. Increased serum sFas and TNFalpha following isolated severe head injury in males. Brain Inj 2007;2I:44I-7.

72. Bermpohl D, You Z, Lo EH, et al. TNF alpha and Fas mediate tissue damage and functional outcome after traumatic brain injury in mice. J Cereb Blood Flow Metab 2007;27:1806-18.

73. Beattie EC, Stellwagen D, Morishita W, et al. Control of synaptic strength by glial TNFalpha. Science 2002;295:2282-5.

74. Hellmich HL, Eidson KA, Capra BA, et al. Injured Fluoro-Jade-positive hippocampal neurons contain high levels of zinc after traumatic brain injury. Brain Res 2007;II27:II9-26.

75. Suh SW, Frederickson CJ, Danscher G. Neurotoxic zinc translocation into hippocampal neurons is inhibited by hypothermia and is aggravated by hyperthermia after traumatic brain injury in rats. J Cereb Blood Flow Metab 2006;26:I6I-9.

76. Frederickson CJ, Maret W, Cuajungco MP. Zinc and excitotoxic brain injury: a new model. Neuroscientist 2004;10:I8-25.

77. Sensi SL, Jeng JM. Rethinking the excitotoxic ionic milieu: the emerging role of $\mathrm{Zn}(2+)$ in ischemic neuronal injury. Curr Mol Med 2004;4:87-III.

78. Capasso M, Jeng JM, Malavolta M, et al. Zinc dyshomeostasis: a key modulator of neuronal injury. J Alzheimers Dis 2005;8:93-108.

79. Geddes-Klein DM, Serbest G, Mesfin MN, et al. Pharmacologically induced calcium oscillations protect neurons from increases in cytosolic calcium after trauma. JNeurochem 2006;97:462-74.

8o. Arundine M, Aarts M, Lau A, et al. Vulnerability of central neurons to secondary insults after in vitro mechanical stretch. JNeurosci 2004;24:8106-23.

8I. Arundine M, Chopra GK, Wrong A, et al. Enhanced vulnerability to NMDA toxicity in sublethal traumatic neuronal injury in vitro. J Neurotrauma 2003;20:1377-95

82. Lau A, Arundine M, Sun HS, et al. Inhibition of caspase-mediated apoptosis by peroxynitrite in traumatic brain injury. JNeurosci 2006;26:11540-53.

83. Ahmed SM, Weber JT, Liang S, et al. NMDA receptor activation contributes to a portion of the decreased mitochondrial membrane potential and elevated intracellular free calcium in strain-injured neurons. JNeurotrauma 2002;19:I6I9-29.

84. Lusardi TA, Wolf JA, Putt ME, et al. Effect of acute calcium influx after mechanical stretch injury in vitro on the viability of hippocampal neurons. J Neurotrauma 2004;2I:6I-72.

85. Halliwell B, Zhao K, Whiteman M. Nitric oxide and peroxynitrite. The ugly, the uglier and the not so good: a personal view of recent controversies. Free Radic Res I999;3I:65I-69.

86. Koppenol WH, Moreno JJ, Pryor WA, et al. Peroxynitrite, a cloaked oxidant formed by nitric oxide and superoxide. Chem Res Toxicol I992;5:834-42.

87. Bayir H, Kagan VE, Clark RS, et al. Neuronal NOS-mediated nitration and inactivation of manganese superoxide dismutase in brain after experimental and human brain injury. JNeurochem 2007;101:I68-8I

88. Radi R, Beckman JS, Bush KM, et al. Peroxynitrite-induced membrane lipid peroxidation: the cytotoxic potential of superoxide and nitric oxide. Arch Biochem Biophys I99I;288:48I-7.

89. Dawson VL, Dawson TM. Deadly conversations: nuclear-mitochondrial cross-talk. J Bioenerg Biomembr 2004;36:287-94.

90. Aarts M, Liu Y, Liu L, et al. Treatment of ischemic brain damage by perturbing NMDA receptor- PSD-95 protein interactions. Science 2002;298:846-50.

Correspondence to: Dr. Andrew J. Baker, St. Michael's Hospital, Bond Wing 7-o86, 30 Bond St., Toronto, ON M5B IW8; fax 416 864-5512; bakera@smh.toronto.on.ca 